Revista Verde de Agroecologia e Desenvolvimento Sustentável

http://www.gvaa.com.br/revista/index.php/RVADS

ARTIGO CIENTÍFICO

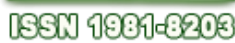

DOI: http://dx.doi.org/10.18378/rvads.v10i3.3046

\title{
Análise espectral e avaliação de índices de vegetação para o mapeamento da caatinga
}

\section{Spectral analysis and evaluation of vegetation indices for mapping caatinga}

Paulo Roberto Megna Francisco ${ }^{1}$, Iede de Brito Chaves ${ }^{2}$, Lucia Helena Garofalo Chaves ${ }^{3}$ Eduardo Rodrigues Viana de Lima ${ }^{4}$, Bernado Barbosa da Silva ${ }^{5}$

RESUMO: A caatinga é um bioma de grande diversidade que cobre a maior parte da área de clima semiárido brasileiro. Várias técnicas já foram utilizadas com o objetivo de determinar quantitativamente e qualitativamente o estado da vegetação a partir de imagens de satélite, e índices de vegetação foram desenvolvidos para auxiliar no mapeamento da vegetação, otimizando parâmetros de medidas espectrais utilizadas com esse fỉm. Este trabalho teve como objetivo analisar e avaliar índices espectrais (NDVI, SAVI e EVI) para mapear a vegetação de caatinga. Concluiu-se que o melhor índice que se correlaciona com a cobertura vegetal da caatinga foi o Normalized Difference Vegetation Index (NDVI), para o período seco, e o padrão de resposta espectral do período seco diminuiu os confundimentos de alvos de vegetação da caatinga. Estimou-se que $29,7 \%$ da área da bacia do rio Taperoá esteja em processo avançado de desertificação.

Palavras chave: análise espectral, índices de vegetação, semiárido

ABSTRACT: The caatinga biome is a large diversity that covers most of the area of Brazilian semi-arid climate. Several techniques have been used in order to determine quantitatively and qualitatively the state of vegetation from satellite images and vegetation indices were developed to assist in vegetation mapping, optimizing spectral measurement parameters used for this purpose. This study aimed to analyze and evaluate spectral indices (NDVI, SAVI and EVI) to map the caatinga vegetation. It was concluded that the best index that correlates with the caatinga vegetation was the Normalized Difference Vegetation Index (NDVI) for the dry period, and the pattern of spectral response of the dry period decreased confounding targets of caatinga vegetation. It was estimated that $29.7 \%$ of the area of the river basin Taperoá is in advanced process of desertification.

Keywords: espectral analysis, semiarid, vegetation index

\footnotetext{
*Autor para correspondência

Recebido para publicação em 30/11/2014; aprovado em: 02/07/2015

${ }^{1}$ Dr. em Eng. Agrícola pela UFCG, Msc. em Manejo de Solo e Água pela UFPB, Tecnólogo em Mecanização Agrícola pela UNESP. E-mail: paulomegna@ig.com.br

${ }^{2}$ Eng. Agrônomo Dr..em Ciência do solo, Prof. aposentado do dep. solos e eng. rural UFPB areia. E-mail: iedebchaves@hotmail.com

${ }^{3}$ Eng. Agrônoma, Dra. Prof do CTRN dep. Eng. agrícola UFCG. E-mail: lhgarofalo@ hotmail.com

${ }^{4}$ Geografo, Dr. em Geografia, Prof. Dep. Geografia CCEN UFPB. E-mail: eduvianalima@gmail.com

${ }^{5}$ Meteorolgista, Dr. em Meteorologia, Prof dep. meteorologia UFCG. E-mail: bernardo@dca.ufcg.edu.br
} 


\section{INTRODUÇÃO}

A caatinga é um bioma exclusivamente brasileiro que cobre grande parte da área de clima semiárido do Nordeste brasileiro (BRASIL, 2005). Caracteriza-se por apresentar uma grande

diversidade de paisagens e segundo Trovão et al. (2007), o estudo e conservação dessa biodiversidade se constituem um dos maiores desafios do conhecimento científico brasileiro.

Conforme Francisco et al. (2012a), várias técnicas já foram estudadas com o objetivo de se determinar quantitativamente e qualitativamente o estado da vegetação a partir de imagens de satélites, e índices de vegetação foram então desenvolvidos a fim de reduzir o número de parâmetros presentes nas medidas multiespectrais. Tais índices têm sido usados na estimativa de vários parâmetros da vegetação (COSTA FILHO et al., 2007) como, por exemplo, a quantidade de biomassa verde (ELVIDGE \& LYON, 1985). Embora muitos índices vegetativos existam, o mais usado e conhecido atualmente é o denominado índice de vegetação da diferença normalizada (NDVI) proposto por Rouse em 1973, que permite o monitoramento da densidade e do estado de vigor da vegetação verde sobre a superfície terrestre (COSTA FILHO et al., 2007).

CHAVES et al. (2008), propôs um método com o qual se pode descrever e avaliar a vegetação da caatinga em seus diferentes estágios de antropização, utilizando-se o Índice de Biomassa da Vegetação Lenhosa (IBVL). É um método de classificação prático, de fácil aplicação auxiliando na interpretação de imagens de satélites.

Na perspectiva moderna de gestão do território, toda ação de planejamento, ordenamento ou monitoramento do espaço deve incluir a análise dos diferentes componentes do ambiente. Como consequência natural, o uso de geoprocessamento em projetos ambientais requer o uso intensivo de técnicas de integração de dados que combine ferramentas de análise espacial, processamento de imagens e geoestatística (CÂMARA \& MEDEIROS, 1998).

$\mathrm{O}$ advento da informática e seu crescente avanço têm possibilitado e estimulado a evolução das chamadas geotecnologias, dos sistemas de informações geográficas (SIG's) e a evolução dos sistemas computacionais para estudos de análise ambiental. A disponibilização de imagens de satélite tem proporcionado excelentes resultados no processo de automação da maioria dos trabalhos executados de forma convencional (ALBUQUERQUE et al., 2012; CARVALHO et al., 2009; CÂMARA \& MEDEIROS, 1996; FERNANDES et al., 1998).

Conforme Calijuri \& Rohm (1994), estes sistemas manipulam dados de diversas fontes como mapas, fotografias aéreas, imagens de satélite, cadastros e outras, permitindo recuperar e combinar informações e efetuar os mais diversos tipos de análise sobre os dados. Neste contexto, conforme Francisco et al. (2011), o sistema de informação geográfica é uma tecnologia que abrange cada vez mais projetos ambientais, sendo um agente facilitador na tomada de decisão.

Portanto este trabalho tem como objetivo analisar e avaliar três índices espectrais a partir de imagens de satélite de média resolução utilizando um sistema de informação geográfica para mapear a vegetação da caatinga, usando o IBVL para validação dos resultados obtidos através dos índices de vegetação multiespectrais.

\section{MATERIAL E MÉTODOS}

A área de estudo compreende a Bacia Hidrográfica do Rio Taperoá (Figura 1), com uma extensão de 5.686,37 km², localizada no Planalto da Borborema, estado da Paraíba cujo principal rio é o Taperoá de regime intermitente. É uma área aberta, sobre o planalto, com relevo suave ondulado, altitudes predominantemente variando entre 400 a $600 \mathrm{~m}$ e drenagem voltada para o leste, o que facilita a penetração uniforme das massas atlânticas de sudeste, propiciando temperaturas amenas $\left(<26^{\circ} \mathrm{C}\right)$, e uma maior amplitude térmica diária. Nas áreas com relevo mais deprimido a precipitação média anual é inferior a 400mm, aumentando a $800 \mathrm{~mm}$ com a altitude, no sentido dos divisores da drenagem (VAREJÃO-SILVA et al., 1984).

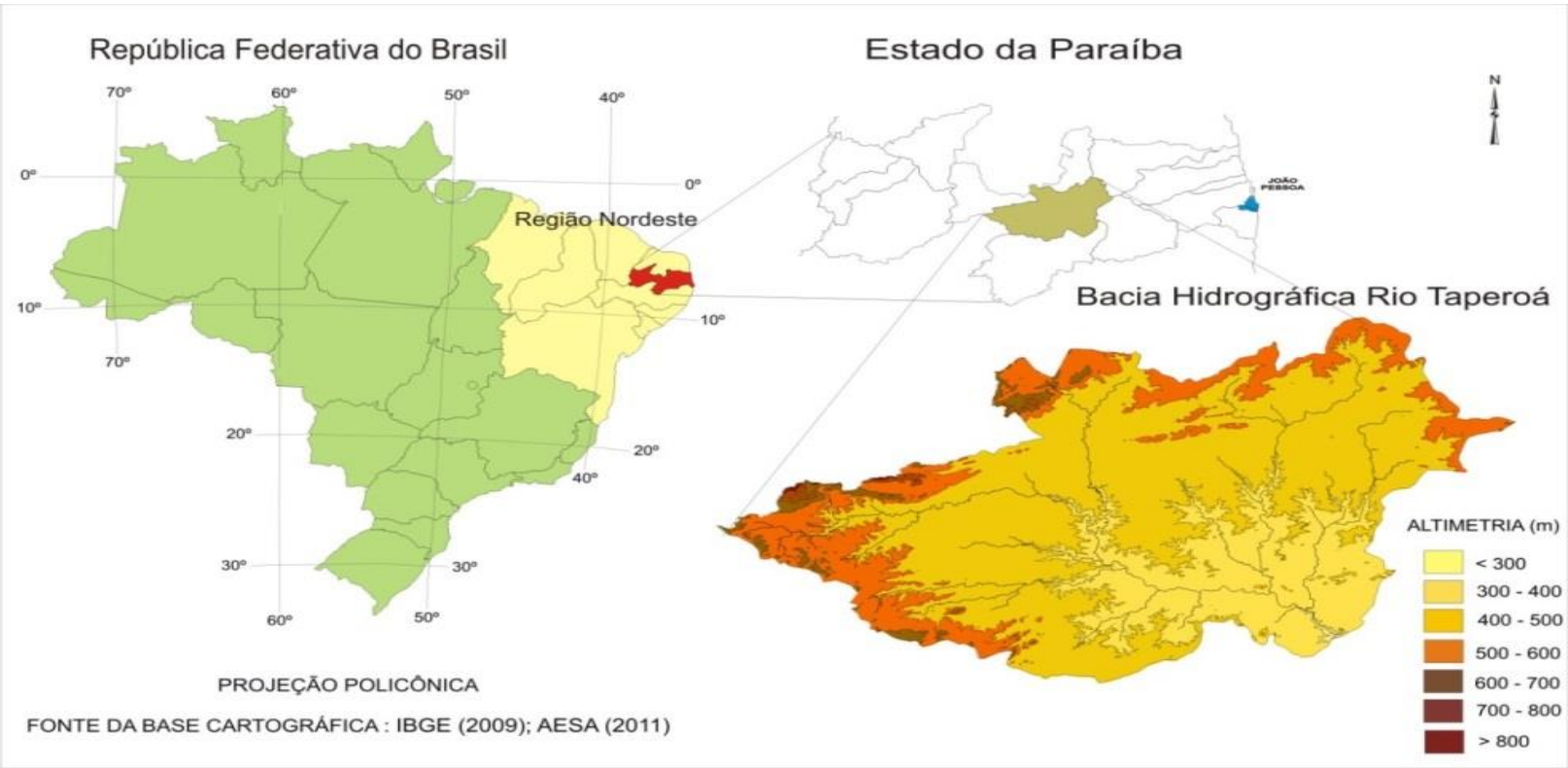

Figura 1. Localização da área de estudo. Fonte: adaptado de IBGE (2009); AESA (2011). 
O clima é do tipo Bsh (semiárido quente), com chuvas apresentando uma forte variação na distribuição espacial, temporal e interanual, e uma estação seca que pode atingir 11 meses (VAREJÃO-SILVA et al., 1984). A vegetação é do tipo caatinga hiperxerófila e de acordo com Barbosa et al. (2007) e Paes-Silva et al. (2003), as espécies mais encontradas são: a Malva (Sida galheirensis Ulbr.), Macambira (Bromelia laciniosa Mart. ex Schult. f.), Imburana (Commiphora leptophloeos (Mart.) J.B.Gillett), Mandacaru (Cereus jamacaru DC.), Xique-xique (Pilosocereus gounellei (F.A.C.Weber) Byles \& G.D.Rowley), Facheiro (Pilosocereus pachycladus F.Ritter), Palmatória (Tacinga palmadora (Britton \& Rose) N.P.Taylor \& Stuppy), Mofumbo (Combretum leprosum Mart.), Marmeleiro (Croton sonderianus Müll.Arg.), Pinhão (Jatropha mollissima (Pohl) Baill.), Pinhão (Jatropha ribifolia (Pohl) Baill.), Jureminha (Desmanthus virgatus (L.) Willd.), Jurema-preta (Mimosa tenuiflora (Willd.) Poir.),
Catingueira (Caesalpinia pyramidalis Tul), Pereiro (Aspidosperma pyrifolium Engl.), Marmeleiro (Croton sonderianus Muell. Arg.), Pinhão bravo (Jatropha molíssima (Pohl.) Mull Arg.) e outras espécies nativas da região como o Angico (Anadenathera macrocarpa (Benth.) Brenan) a Aroeira (Myracrodruon urundeuva Allemão) e o Umbu (Spondias tuberosa, L.).

Os solos na área de estudo (Figura 2) são o Luvissolo Crômico Vértico fase pedregosa relevo suave ondulado, predominante em grande parte da região; os Vertissolos relevo suave ondulado e ondulado predominam nas partes mais baixas e o Planossolo Nátrico, relevo plano e suave ondulado, que ocorre ao norte, ao longo da BR-230, trecho Campina Grande - Juazeirinho, na bacia do rio Taperoá. Nas áreas mais acidentadas, ocorre o Neossolo Litólico Eutrófico fase pedregosa substrato gnaisse e granito, segundo FRANCISCO (2010), baseado em PARAÍBA (1978).

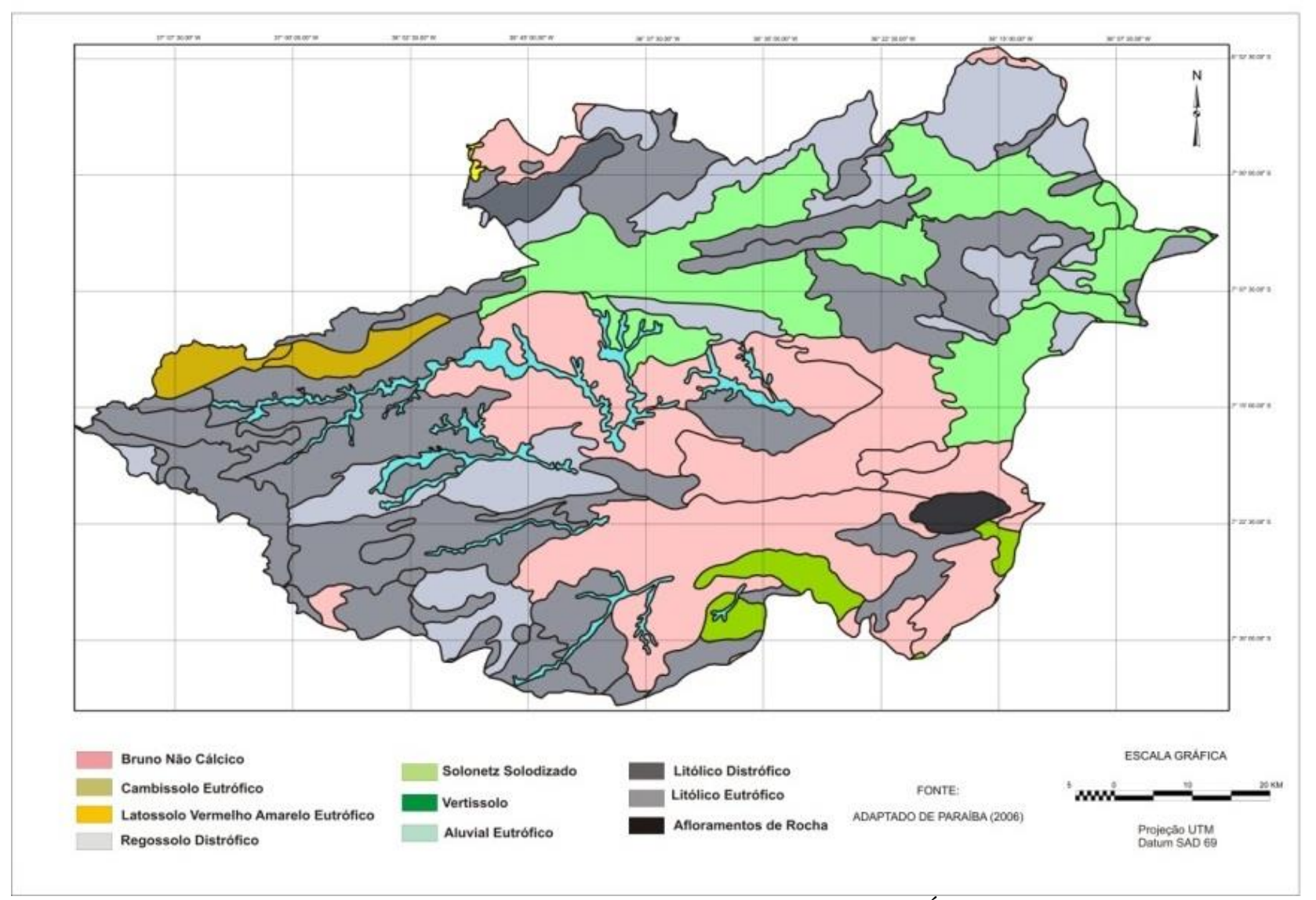

Figura 2. Solos da área de estudo. Fonte: Adaptado de PARAÍBA (2006).

Neste trabalho foram utilizadas imagens do satélite TM/LANDSAT 5, órbita 215, ponto 65 de 28/10/2009 (período seco) e de 24/05/2010 (período úmido), disponibilizadas pelo INPE. O Google Earth online foi utilizado para pré-selecionar os 212 alvos terrestres representativos dos diferentes tipos de vegetação da área de estudo. As áreas pré-selecionadas foram visitadas para que fosse possível georreferenciar, descrever e avaliar a vegetação em seus diferentes estágios de antropização utilizando o Índice de Biomassa da Vegetação Lenhosa (IBVL), método proposto por Chaves et al. (2008). 


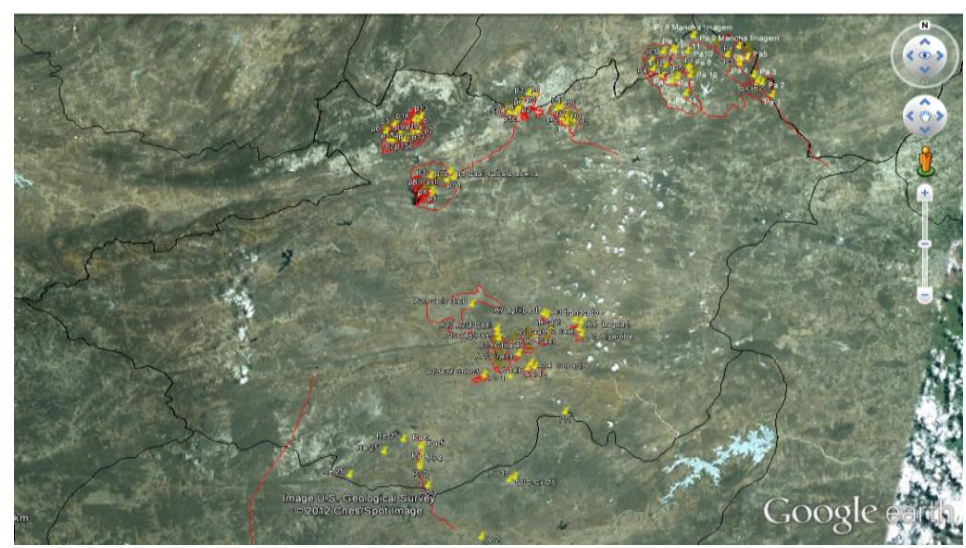

Figura 3. Espacialização dos pontos amostrais na bacia hidrográfica do rio Taperoá, PB.

As imagens foram tratadas utilizando o software ERDAS 8.5, onde foram executadas as correções radiométricas, e obtidas as cartas de radiância e reflectância, de acordo com o modelo obtido por BASTIAANSSEN et al. 2005 (SILVA et al., 2005a).

Foi desenvolvido um modelo com o Model Maker do ERDAS, destinado às tarefas de calibração radiométrica. Neste procedimento foi utilizada a Equação 1 proposta por Markham \& Baker (1987):

$$
\frac{L_{\lambda \mathrm{i}}=a_{i}+b_{i}-a_{i}}{255} * N D
$$

Em que: $a_{i}$ e $b_{i}$ são as radiâncias espectrais mínima e máxima $\left(\mathrm{W} \mathrm{m} \mathrm{mr}^{-1} \mu \mathrm{m}^{-1}\right.$ ), ND é a intensidade do pixel (número inteiro de 0 a 255) e i $=1,2,3,4,5,6$ e 7 , corresponde às bandas 1 , 2, 3, 4, 5, 6 e 7 .

De posse dos mapas de radiância espectral de cada banda, informações sobre o cosZ e irradiância espectral no topo da atmosfera (Tabela 1) para cada banda, estimou-se a refletância espectral planetária em cada banda, através da equação 2 (BASTIAANSSEN, 1995):

$$
r_{p i}=\frac{L_{\lambda} * \pi}{K \lambda * \cos Z * d r}
$$

Em que: $r_{p i}$ é refletância planetária da banda $i, K_{\lambda}$ é a irradiância solar espectral no topo da atmosfera (Tabela 1), Z é o ângulo zenital do Sol e dr é o inverso do quadrado da distância relativa Terra - Sol - ds, em unidades astronômicas, que é dada pela equação 3 :

$$
\begin{aligned}
& d s \\
& =1+0,0167 \operatorname{sen}\left[\frac{2 \pi(J-93,5)}{365}\right]
\end{aligned}
$$

Em que: J é o dia Juliano e o argumento da função seno se encontra em radiano. Por sua vez, o ângulo Zenital do Sol não precisou ser calculado, pois o mesmo se encontrava disponível no cabeçalho das imagens adquiridas para este trabalho.

Tabela 1. Descrição das bandas do Mapeador Temático (TM) do LANDSAT 5, com os correspondentes intervalos de comprimento de onda, coeficientes de calibração (radiância mínima - a e máxima - b) e irradiâncias espectrais no topo da atmosfera (TOA)

\begin{tabular}{ccccc}
\hline Bandas & $\begin{array}{c}\text { Comprimento de Onda } \\
(\mu \mathrm{m})\end{array}$ & $\begin{array}{c}\text { Coeficientes de Calibração } \\
\left(\mathrm{Wm}^{-2} \mathrm{sr}^{-1} \mu \mathrm{m}^{-1}\right)\end{array}$ & $\begin{array}{c}\text { Irradiância Espectral no } \\
\text { Topo da Atmosfera } \\
\left(\mathrm{Wm}^{-2} \mu \mathrm{m}^{-1}\right)\end{array}$ \\
\hline 1 (azul) & $0,45-0,52$ & $\mathrm{a}$ & $\mathrm{b}$ & 1957 \\
2 (verde) & $0,52-0,60$ & $-1,52$ & 193,0 & 1826 \\
3 (vermelho) & $0,63-0,69$ & $-1,17$ & 365,0 & 1554 \\
4 (IV-próximo) & $0,76-0,79$ & $-1,51$ & 264,0 & 1036 \\
5 (IV-médio) & $1,55-1,75$ & $-0,37$ & 30,2 & 215,0 \\
6 (IV-termal) & $10,4-12,5$ & 1,2378 & 15,303 & - \\
7 (IV-médio) & $2,08-2,35$ & $-0,15$ & 16,5 & 80,67 \\
\hline
\end{tabular}

Fonte: Allen et al. (2002).

As etapas seguintes correspondentes ao índice de vegetação estão bem descritas em SILVA et al. (2005b). Para a obtenção do Índice de Vegetação da Diferença Normalizada (NDVI) foi utilizada a equação 4, para o cálculo do SAVI (Índice de Vegetação com Ajuste do Solo) foi utilizado a equação 5, e o EVI (Índice de Vegetação Aumentada) foi calculado através da equação 6 :

$$
\begin{aligned}
& N D V I=\frac{(\mathrm{NIR}-\mathrm{RED})}{(\mathrm{NIR}+\mathrm{RED})} \\
& S A V I=\left(\frac{\mathrm{NIR}-\mathrm{RED}}{N I R+R E D}+\mathrm{L}\right)(1+\mathrm{L}) \\
& E V I=G\left(\frac{\mathrm{NIR}-\mathrm{RED}}{N I R+C 1 R E D-C 2 A+L}\right)
\end{aligned}
$$


Em que: NIR = banda $4 ; \mathrm{RED}=$ banda $3 ; \mathrm{A}=$ banda $1 ; \mathrm{L}=1$; $\mathrm{C}_{1}=6 ; \mathrm{C}_{2}=7,5$ e o fator de ganho $\mathrm{G}=2,5$ (HUETE et al., 2002).

Após a obtenção das imagens-índices de vegetação foi realizada a extração dos valores de seis pixels em torno de cada ponto georreferenciado do campo de observação, criando uma planilha no $\mathrm{EXCEL}^{\circledR}$ com os valores dos índices, a média destes valores, as informações obtidas em campo da vegetação com as classes de maior predominância de porte e recobrimento, como também o cálculo de seus respectivos valores de IBVL onde foram definidas 9 classes de cobertura vegetal (Tabela 2). Ao final foram realizadas análises estatísticas de correlação entre NDVI, SAVI, EVI e o IBVL para selecionar o melhor índice.

Tabela 2. Classes de vegetação e valores de refletância

\begin{tabular}{cc}
\hline Classes de IBVL & Valores de NDVI \\
\hline Arbórea muito densa & $>0,350$ \\
Arbórea densa & 0,320 a 0,350 \\
Subarbórea densa & 0,300 a 0,320 \\
Subarbórea Arbustiva densa & 0,285 a 0,300 \\
Arbustiva Subarbórea densa & 0,265 a 0,285 \\
Arbustiva Subarbórea aberta & 0,250 a 0,265 \\
Arbustiva Subarbustiva aberta & 0,225 a 0,250 \\
Subarbustiva Arbustiva rala & 0,200 a 0,225 \\
Subarbustiva Arbustiva muito rala & 0,150 a 0,200 \\
Solo exposto & 0,000 a 0,150 \\
Corpos d'água & -1 a 0,000 \\
\hline
\end{tabular}

Dos 222 pontos de observações descritos em campo foram selecionados 51 pontos representativos para uma faixa ampla de padrões de biomassa eliminando-se padrões com maiores números de repetições.

Para determinação das classes de vegetação e seus limites foi realizada uma curva teórica de correlação selecionando leituras crescentes de valores de biomassa deixando-se três pontos representativos para cada classe de vegetação estabelecida. A partir da reta teórica de determinação foram escalonados limites fixos para as classes de biomassa (IBVL) e determinados os valores limites correspondentes de NDVI pela equação da reta.

Com o objetivo de mapear a vegetação de caatinga através do índice selecionado, foi criada uma base de dados no SPRING 5.2.2, na projeção UTM/SAD69, importando as imagens-índices de vegetação e classificando-as com a utilização do programa LEGAL de acordo com a Tabela 2.

\section{RESULTADOS E DISCUSSÃO}

Nos histogramas de reflectância das imagens do período seco (Figura 4) das Bandas 1, 3 e 4, observa-se que os valores médios são de $0,112,0,128$ e 0,236 , respectivamente. Os valores mínimos encontrados foram de $-0,001$ para todas as imagens, e os valores máximos foram $0,319,0,574$ e 0,816 respectivamente.

Para as imagens de 24/05/2010 (período úmido) (Figura 5), das Bandas 1(a), 3(b) e 4(c), os histogramas apresentaram valores médios de reflectância de $0,101,0,095$ e 0,239 respectivamente. Os valores mínimos encontrados foram de $0,002,-0,001$ e - $-0,003$, e os valores máximos foram de 0,374 , 0,674 e 0,958 respectivamente.

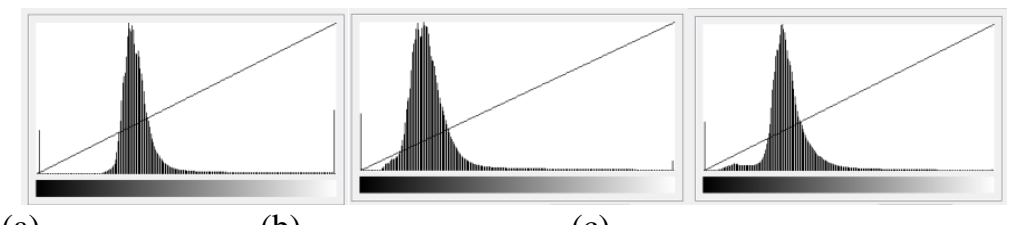

(a)

(b)

(c)

Figura 4. Histogramas das refletâncias na imagem de 29/10/2009 (período seco) do satélite TM/ LANDSAT 5. Banda 1(a), Banda 3(b) e Banda 4(c).

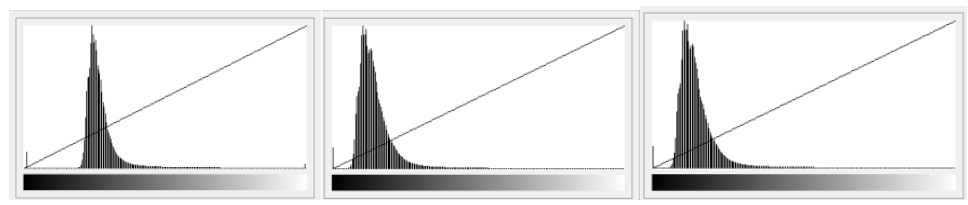

(a)

(b)

(c)

Figura 5. Histogramas das reflectâncias das imagens de 24/05/2010 (período úmido) do TM/ LANDSAT 5. Banda 1(a), Banda 2(b) e Banda 3(c).

Segundo Parkinson (1997), valores típicos de NDVI para florestas úmidas tropicais são da ordem de 0,6. Kaufman \& Holben (1993), encontraram em algumas regiões do Nordeste valores de NDVI entre 0,15 e 0,62. Lopes et al. (2010), avaliando mudanças na cobertura vegetal a partir do
NDVI, na bacia hidrográfica do rio Brígida (Pernambuco), obtiveram respectivamente valores mínimo, máximo e médio para o ano de 1985 da ordem de 0,09, 0,24 e 0,12. Para 2001, os valores obtidos foram de 0,09, 0,42 e 0,14. Sá et al. (2008), avaliando o NDVI na região do Araripe Pernambucano, 
relatam que o valor mínimo encontrado foi de $-0,74$ e o máximo de 0,796 , o valor médio foi de 0,282 . Os valores de NDVI entre 0,201 e 0,278, correspondem a uma vegetação de Savana Estépica Arborizada e Florestada que se encontram degradada. Nas áreas de Mata Ciliar o NDVI variou entre 0,490 a 0,797 (FRANCISCO et al., 2012b).

As variações de refletância na região do visível estão associadas à concentração de clorofila e de outros pigmentos em diferentes estágios de desenvolvimento da folha (KUMAR, 1972). Maldonado (2005) mostra que para a caatinga, a radiância do infravermelho próximo é sempre maior que a do vermelho e que para a época seca, de forma similar, a radiância diminui com o aumento da biomassa; enquanto que, na época úmida, a diferença da radiância entre as bandas aumenta, devido a maior absorção da energia do vermelho pela fotossíntese com o aumento da biomassa e pela maior reflexão do infravermelho pela água de hidratação da folhagem.

Considerando que a maioria dos índices de vegetação se utiliza deste comportamento radiométrico entre estas bandas espectrais, pode se observar na Figura 6, que os valores dos índices cresceram com o aumento da biomassa (IBVL), e que praticamente dobrou na época úmida em relação á época seca. A maior dispersão dos dados para o período úmido confirma esta ser uma época inadequada para trabalhos de classificação e mapeamento da vegetação da Caatinga.

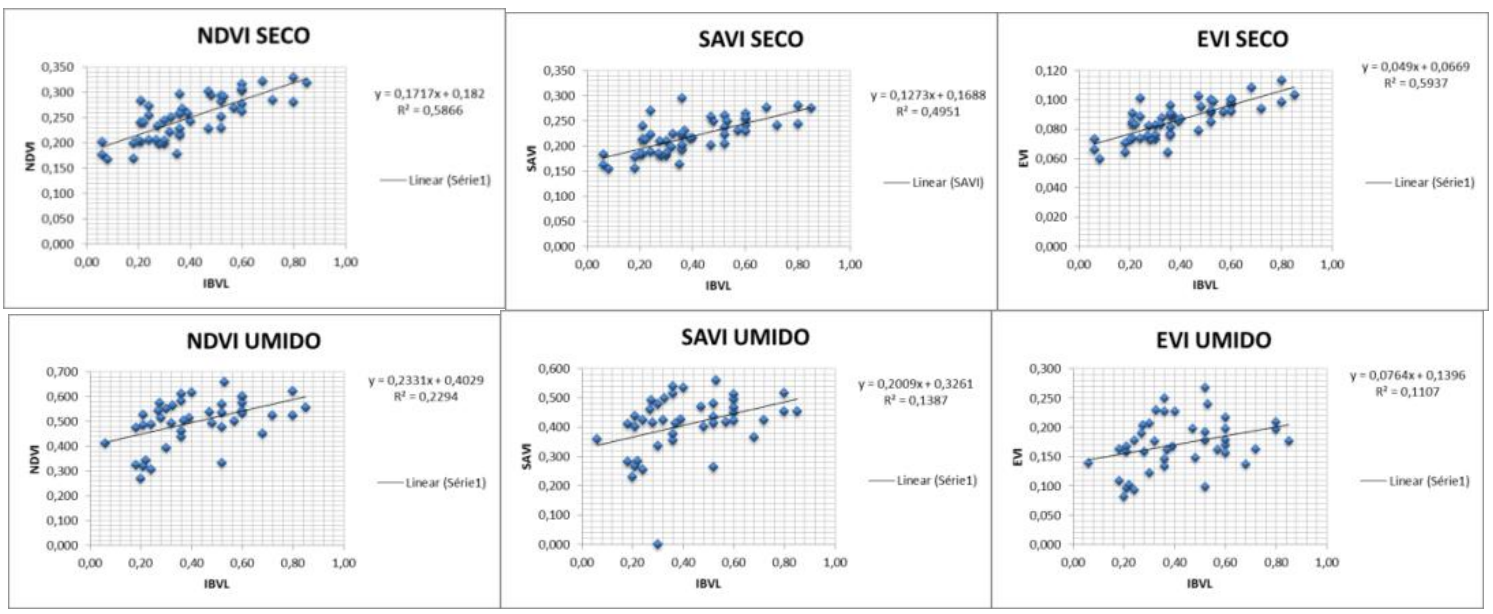

Figura 6. Correlação do IBVL com os índices de vegetação (NDVI, SAVI e EVI).

Observa-se para o período úmido (Figura 6) que muitas das áreas com vegetação aberta, valores de IBVL variando de 0,200 a 0,400, apresentam valores de NDVI, SAVI e EVI iguais aos de áreas com vegetação de porte maior e mais denso, de IBVL 0,800 e 0,850, por exemplo. Estes dados confirmam as observações feitas por Maldonado (1999; 2005) em que, na Caatinga, a diversidade de comportamento e espécies na recomposição da vegetação é intensa com a chegada das primeiras chuvas.

No período úmido, áreas mais abertas, com solos férteis e conservados, o manto herbáceo e graminóide formado de plantas colonizadoras, como o Mata-pasto (Chromolaena maximilianii. Schrad) e o Marmeleiro (Croton blanchetianus. Baill), recobrem os espaços entre as árvores e, por serem jovens e terem alta capacidade fotossintética, absorvem mais energia luminosa, dando respostas espectrais semelhantes ou até maiores que as das áreas com vegetação adulta, arbórea e mais densa (FRANCISCO, 2013).

Os baixos valores das leituras dos índices NDVI, SAVI e EVI, para o período úmido, para alguns pontos com IBVL em torno de 0,20, devem representar áreas degradadas. Neste caso, áreas com solos degradados perdem a capacidade de restabelecimento da cobertura vegetal, e daí os mais baixos valores de leituras espectrais. Observações semelhantes foram feitas por Francisco et al. (2012b) avaliando a influência da umidade antecedente nas leituras do NDVI. Esta também é uma técnica de identificação de áreas degradadas utilizada na modelagem da desertificação no programa DesertWatch Extention project (DESERTWATCH, 2012).

Nas correlações entre o IBVL e os diferentes índices espectrais (Figura 6) pode se observar que o período seco é a melhor época para se estudar a caatinga, uma vez que, proporcionalmente, todos os índices apresentaram neste período os maiores coeficientes de correlação.

Para as leituras do período seco (Figura 6) as correlações com o índice de biomassa IBVL são mais altas que no período úmido, para NDVI, SAVI e EVI, fato que demonstra menor dispersão dos dados de leituras. O período seco tem se consagrado como a melhor época para se realizar o diagnóstico e o mapeamento da vegetação de Caatinga, conforme constatado também por Guimarães (2009), Oliveira et al. (2009), Lopes et al. (2010) e Chaves et al. (2012).

O EVI e o NDVI apresentaram as melhores correlações com valores de IBVL, com $\mathrm{r}^{2}=0,5937$ e $r^{2}=0,5866$, respectivamente, demonstrando ter praticamente a mesma confiabilidade de determinação. Resultados semelhantes foram encontrados por Oliveira et al. (2009).

Os valores das leituras do NDVI para vegetação da Caatinga no período seco (Figura 5) variaram de 0,180 a 0,340 para valores de IBVL de 0,05 a 0,85 , respectivamente; enquanto que, os valores das leituras do EVI oscilaram de 0,068 a 0,108 para os mesmos valores de IBVL. Considerando esta estreita faixa de amplitude das leituras do EVI optou-se por trabalhar com o NDVI, visando facilitar a discriminação dos limites das classes de vegetação, além de que, o NDVI é um índice mais amplamente utilizado.

$\mathrm{Na}$ análise estatística da imagem-índice de vegetação do NDVI, os valores mínimos e máximos encontrados variam de -0,991 a 0,813, com uma média de 0,252, e um desvio padrão de 0,075. No histograma da Figura 7, observa-se a curva de distribuição dos valores de refletância da imagem, 
demonstrando uma maior frequência dos pixels entre 0,2 e 0,3 de leituras.

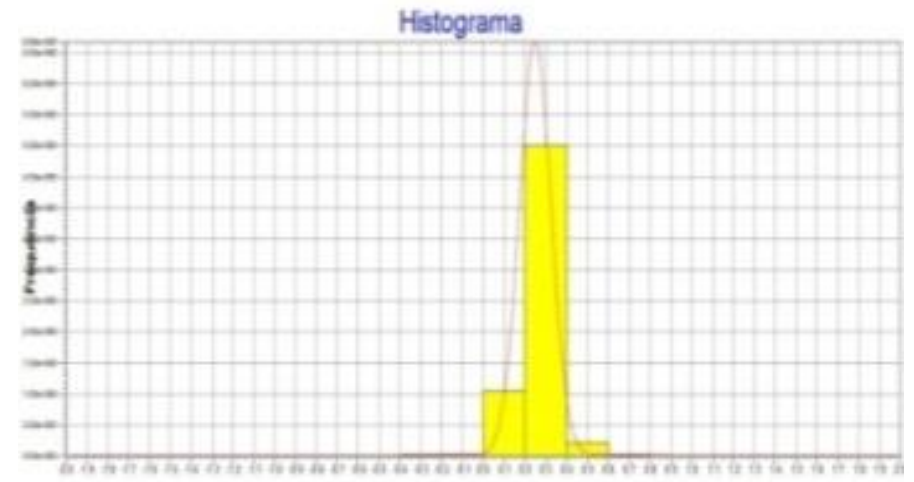

Figura 7. Histograma de distribuição dos valores de reflectância.

Morais et al. (2011), encontraram trabalhando em área de transição de Caatinga bem preservadas de floresta subcaducifólia no município de Floresta, PE, leituras de NDVI variando de 0,208 a 0,803. Valores de NDVI abaixo de 0,4 para o período seco são mais compatíveis para respostas da vegetação de Caatinga hiperxerófila, como a da área de estudo (PAIXÃO et al., 2009; LOPES et al., 2010; CHAVES et al., 2012).

Uma vez que os índices de vegetação são muito sensíveis à atividade fotossintética e as espécies de Caatinga apresentam diversos mecanismos adaptativos à captação e uso de água (COPPIN et al., 2004;
MALDONADO, 2005), a detecção de mudanças da vegetação de Caatinga, pode muitas vezes, estar influenciada por diferenças das condições de umidade. Francisco et al. (2012b), observaram numa análise temporal da bacia do rio Taperoá, falsas detecções de mudanças influenciadas pela variação das condições de umidade espacial e temporal.

Na Figura 8, observa-se o mapa da classificação da vegetação de caatinga e na Tabela 3 , os valores em área e percentagem de ocupação das classes de vegetação e cobertura da terra.

Tabela 3. Distribuição das classes de vegetação

\begin{tabular}{ccc}
\hline Classes & $\left(\mathrm{km}^{2}\right)$ & $\%$ \\
\hline Arbórea muito densa & 420,54 & 7,39 \\
Arbórea densa & 281,94 & 4,95 \\
Subarbórea densa & 344,79 & 6,07 \\
Subarbórea arbustiva densa & 370,25 & 6,52 \\
Arbustiva subarbórea densa & 668,31 & 11,75 \\
Arbustiva subarbórea aberta & 584,17 & 10,28 \\
Arbustiva subarbustiva aberta & $1.103,70$ & 19,41 \\
Subarbustiva arbustiva rala & 917,93 & 16,14 \\
Subarbustiva arbustiva muito rala & 712,90 & 12,53 \\
Solo exposto & 56,26 & 0,99 \\
Corpos d'água & 32,28 & 0,57 \\
Nuvens & 193,30 & 3,40 \\
\hline Área Total & $5.686,37$ & 100,00 \\
\hline
\end{tabular}

Em uma análise conjunta da bacia hidrográfica (Figura 8), pode-se observar que o terço sudoeste é onde se concentra o maior percentual de áreas com vegetação de maior porte e densidade.

Observa-se que existe uma estreita relação entre áreas mais altas (500 a 700m) e solos Litólicos com unidades mais densas de vegetação, estas representadas pela classe Arbórea muito densa, Arbórea densa, Subarbórea densa, Subarbórea arbustiva densa (Figura 9) e Arbustiva subarbórea densa, que ocupam 420,54 km², 281,94 km², 344,79 km², 370,25 km e $688,31 \mathrm{~km}^{2}$ respectivamente correspondendo, no conjunto a $36,68 \%$ da área da bacia (Tabela 3).

Paes-Silva et al. (2003) e Guimarães (2009), trabalhando em sub-bacias desta área de estudo, também observaram esta relação entre vegetação e áreas declivosas e de difícil acesso
Acompanhando a linha do divisor de oeste para nordeste, a vegetação mais densa recobre as áreas mais declivosas, associadas aos solos Litólicos e Cambissolos Eutrófico. Seguindo esta mesma linha do divisor na área central, pode se observar uma grande área vegetada associada ao solo Litólico originário de quartzito e filito da serra da Viração. Após a serra, apesar da altitude próxima a $600 \mathrm{~m}$, o relevo é suave na linha do divisor com a ocorrência dos solos Neossolos Regolíticos, área agrícola densamente povoada; em seguida, a nordeste nas nascentes do rio de Soledade, ocorrem inúmeros fragmentos de vegetação densa sugerindo áreas protegidas de reserva legal de propriedades, apesar da ocorrência de solos Neossolos Regolíticos, potencialmente agrícolas (Figura 10). 


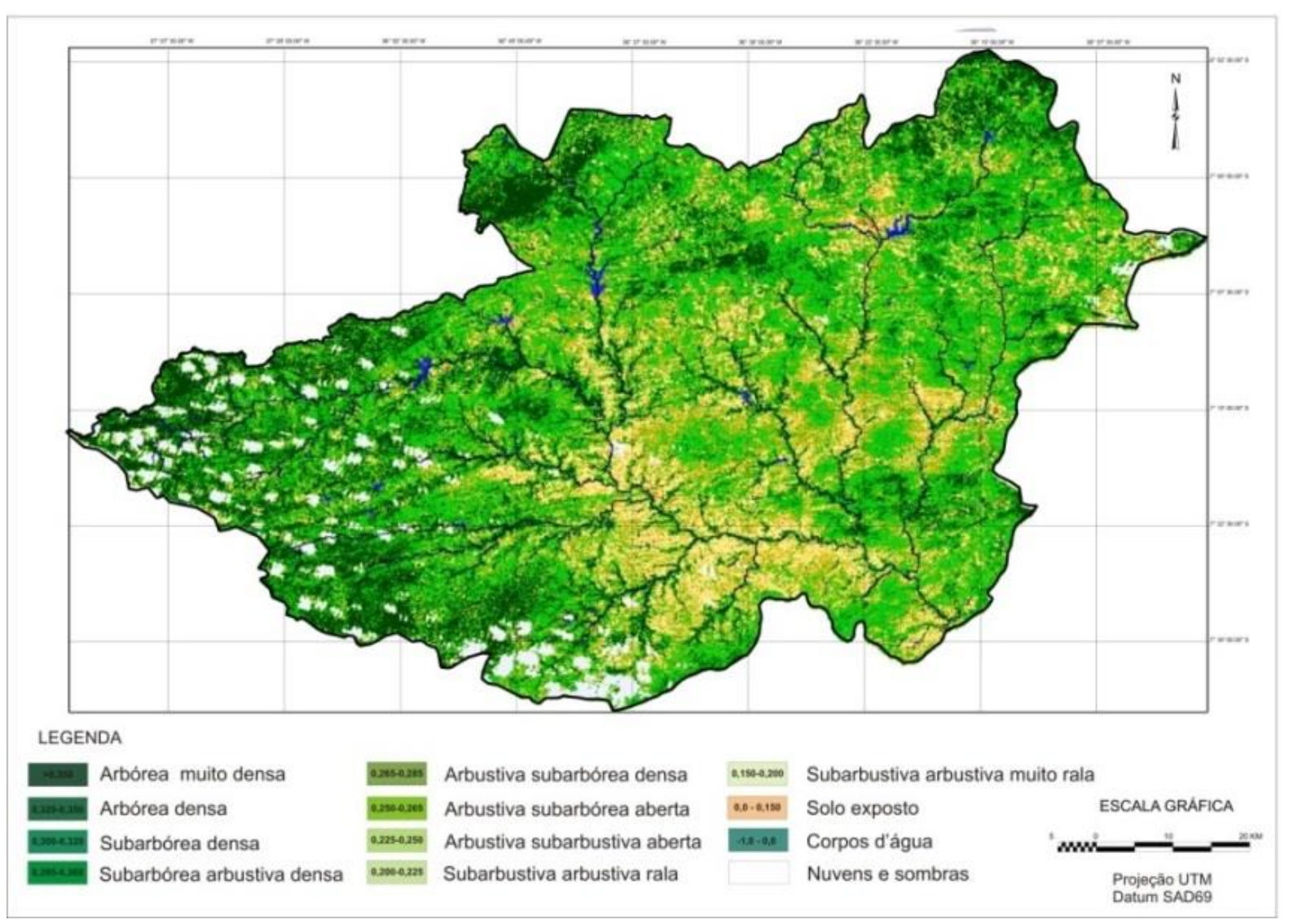

Figura 8. Mapa de tipologias de vegetação de caatinga.

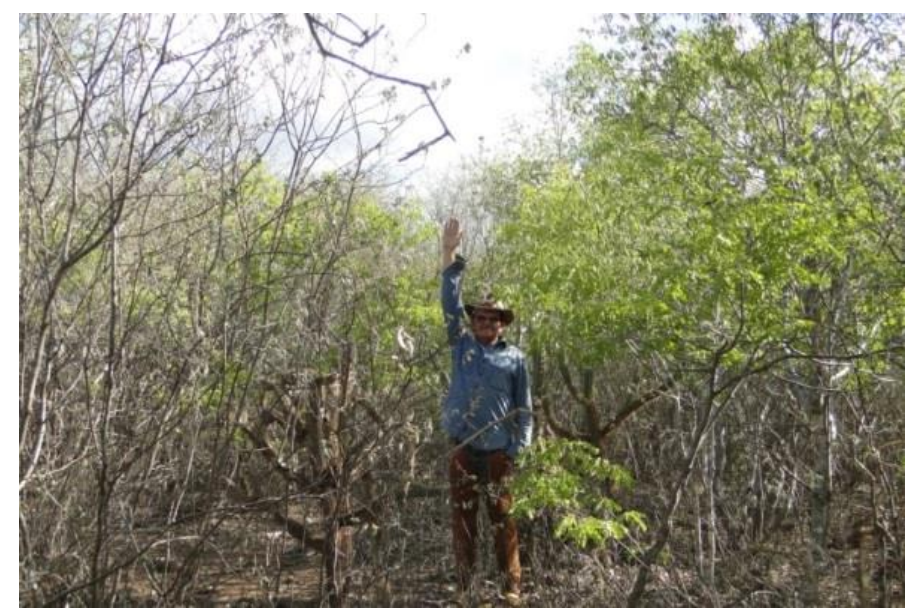

Figura 9. Vegetação de Caatinga classe Subarbórea arbustiva densa.

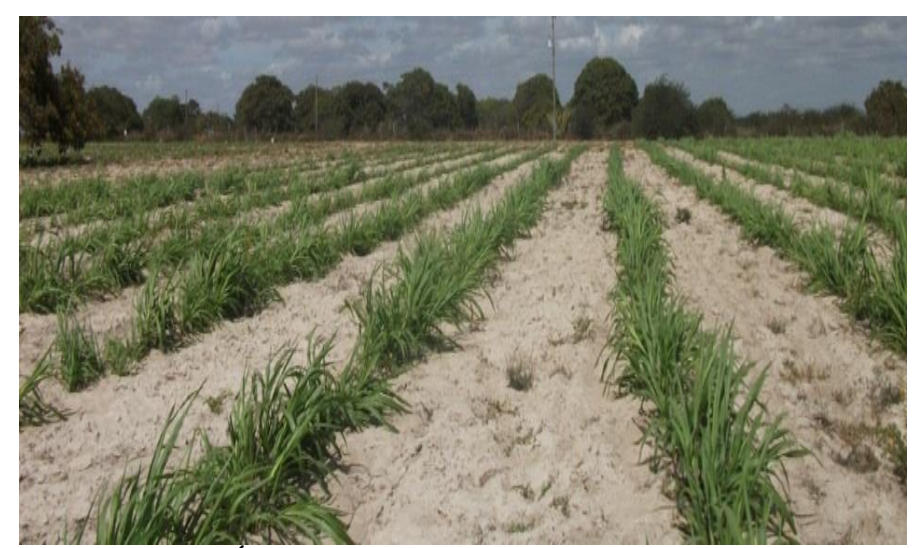

Figura 10. Área de Neossolo Regolítico com agricultura. 
Ainda associada à altitude e solos Litólicos, destaca-se uma área de vegetação densa, na área centro norte da bacia, que corresponde a uma linha de serra, divisor interno de subbacias, e a sudeste, próximo à foz do rio Taperoá, áreas de Afloramentos rochosos associados aos solos Litólicos.

As áreas mais desnudas de vegetação estão mais próximas da drenagem e aumentam na medida em que diminui de altitude e se aproximam do ponto de deságue da bacia. As classes, solo exposto (Figura 11), e Subarbustiva arbustiva muito rala (Figura 12), com 56,26 km² e 712,9 km² (Tabela 3) respectivamente, que corresponde a $13,02 \%$ da área total da bacia, ocorrem numa grande extensão ao longo do terço

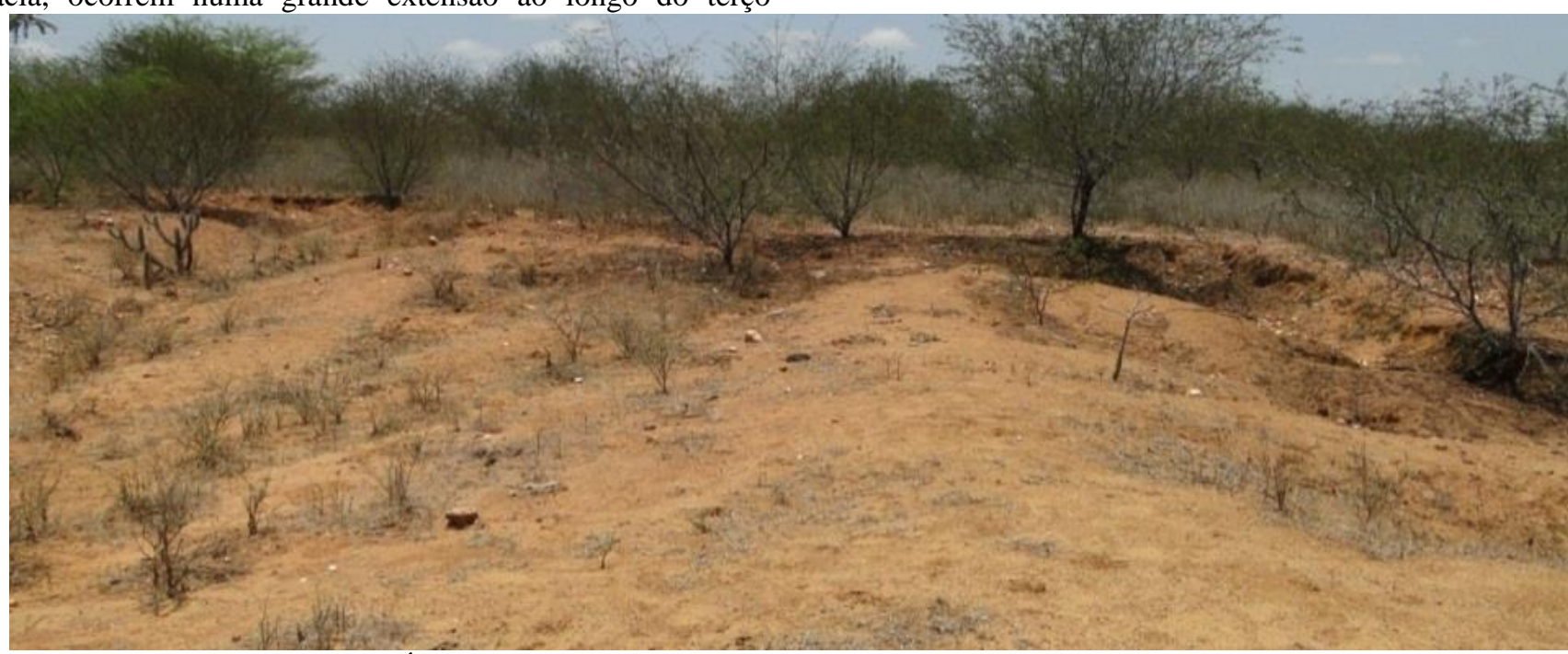

Figura 11. Área de solo exposto resultante da erosão em Luvissolo Crômico vértico.

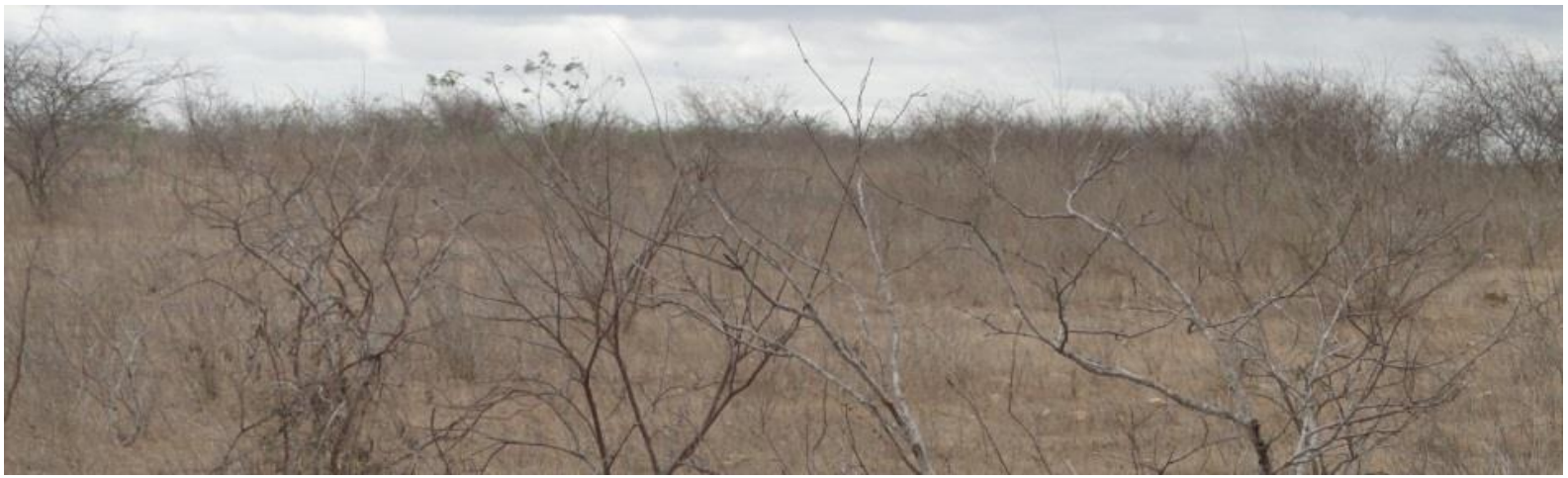

Figura 12. Vegetação de Caatinga classe Subarbustiva arbustiva muito rala.

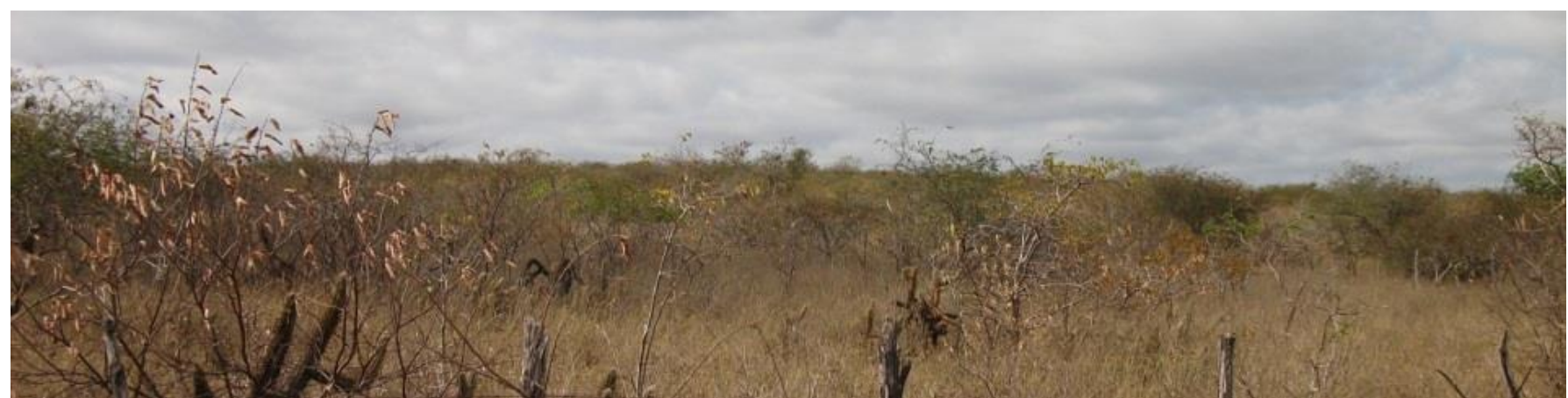

Figura 13. Vegetação de Caatinga classe Subarbustiva arbustiva rala.

As áreas abertas com vegetação das classes Arbustiva subarbustiva aberta, com $1.103,7 \mathrm{~km}^{2}$ e Arbustiva subarbórea aberta, com $584,37 \mathrm{~km}^{2}$, correspondem a $29,69 \%$ da área da médio inferior do rio Taperoá. Enquanto que a classe Subarbustiva arbustiva rala (Figura 13) que, isoladamente, ocupa $917,93 \mathrm{~km}^{2}$, e corresponde a $16,14 \%$ da área total, se distribui em grande parte, nos interflúvios mais baixos da drenagem, abaixo da cota de $450 \mathrm{~m}$. Acima desta cota passa a ocorrer em parte dos interflúvios e no terço inferior das encostas ao longo dos canais de drenagem.

Por não se conseguir discriminar neste trabalho as áreas de uso agrícola, pastagem e bosques abertos de algaroba, estas estão incluídas nas áreas mapeadas de vegetação mais rala e desnuda, representando áreas degradadas ou não 
e serras. Em grande parte essas áreas abertas são de pastagem natural para o rebanho bovino (Figura 14).

Pode se considerar que com o apoio das descrições da vegetação em campo pôde se aprimorar o inventário da cobertura do solo, utilizando-se do melhor padrão de resposta espectral do período seco, que ajudou a diminuir os confundimentos de alvos e identificar e quantificar com boa precisão as áreas de vegetação de caatinga.
Considerando a intempestividade das chuvas da região semiárida brasileira, em particular com ocorrência de chuvas de alto potencial erosivo, a cobertura vegetal do solo é de fundamental importância para protegê-lo. Neste caso, pode se afirmar, com certo grau de certeza, que as áreas com caatinga Subarbustiva arbustiva rala e de menor de recobrimento, que correspondem a $1.687,99 \mathrm{~km}^{2}$ (29,67\% da bacia), encontramse em processo avançado de desertificação.

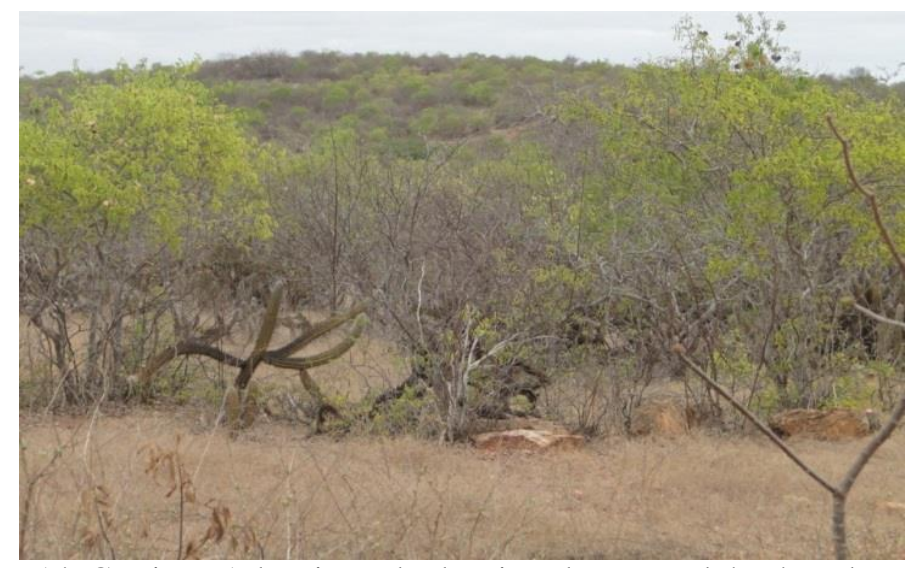

Figura 14. Caatinga Arbustiva subarbustiva aberta, também área de pastejo.

\section{CONCLUSÕES}

O período seco foi a melhor época para se realizar o diagnóstico e o mapeamento da vegetação de Caatinga.

O EVI e o NDVI apresentaram as melhores correlações com valores de IBVL, com $\mathrm{r}^{2}=0,5937$ e $r^{2}=0,5866$, respectivamente, com praticamente a mesma confiabilidade de determinação.

O NDVI por apresentar maior dispersar dos valores de leituras e ser o índice de vegetação mais conhecido e utilizado foi o selecionado para realização deste trabalho.

Os valores mínimos e máximos de NDVI para o período seco variaram de $-0,991$ a 0,813 , com uma média de 0,252 , e um desvio padrão de 0,075 .

A metodologia utilizada permitiu segmentar os dados em nove classes de vegetação, representando valores crescentes de biomassa lenhosa.

Padrões de vegetação mais alto e mais denso recobrem $36,68 \%$ da área da bacia, sendo mais frequentes de ocorrerem nas áreas mais altas, declivosas e distantes das povoações, em solos rasos e pedregosos.

As áreas com vegetação rala e de menor porte, incluídas as áreas desnudas, estão mais próximas da drenagem e aumentam na medida em que diminui de altitude e se aproximam do ponto de deságue da bacia, ocorrendo em $29,66 \%$ da área.

Considerando a intempestividade das chuvas da região semiárida, pode se afirmar, com certo grau de certeza, que as áreas com caatinga Subarbustiva arbustiva rala e de menor grau de recobrimento, que correspondem a $1.687,99 \mathrm{~km}^{2}$ (29,67\% da bacia), encontram-se em processo avançado de desertificação.

\section{AGRADECIMENTOS}

À CAPES pela concessão da bolsa de estudo ao primeiro autor e ao $\mathrm{CNPq}$ pelo apoio financeiro através do Projeto de Pesquisa n. ${ }^{\circ}$ 35/20109 INSA/CT-HIDRO-CNPq.

\section{REFERÊNCIAS BIBLIOGRÁFICAS}

AESA. Agência Executiva de Gestão das Águas do Estado da Paraíba. Disponível em: http://www.aesa.pb.gov.br. Acesso m 25 de março de 2011.

ALBUQUERQUE, E. L. S.; MEDEIROS, C. N.; GOMES, D. D. M.; CRUZ, M. L. B. Sig-web Ceará em mapas interativos, novas ferramentas na cartografia escolar. Mercator, v.11, n.24, p.253-269, 2012.

ALLEN, R.; BASTIAANSSEN, W.; WATERS, R.; TASUMI, M.; TREZZA, R. Surface energy balance algorithms for land (SEBAL). Idaho implementation Advanced Training and User's Manual, 1997. p.2002.

BARBOSA, M. R. V.; LIMA, I. B. DE; LIMA, J. R.; CUNHA, J. P. DA; AGRA, M. DE F.; THOMAS, W. W. Vegetação e flora no Cariri paraibano. Oecologia Brasiliensis, v.11, n.3, p.313-322, 2007.

BASTIAANSSEN W. G. M.; NOORDMAN E. J. M.; PELGRUM H.; DAVIDS G.; ALLEN R. G. SEBAL for spatially distributed ET under actual management and growing conditions. ASCE Journal of Irrigation and Drainage Engineering, p.85-93, 2005.

BRASIL. Ministério do Meio Ambiente, Secretaria de Recursos Hídricos. Programa de Ação Nacional de Combate à Desertificação e Mitigação dos Efeitos da Seca - PAN-Brasil. Brasília-DF, 2005, 213p.

CALIJURI, M. L.; ROHM, S. A. Sistemas de informações geográficas. Viçosa: Imprensa Universitária, 1993. 34p.

CÂMARA, G.; SOUZA R. C. M.; FREITAS U. M.; GARRIDO, J. SPRING: Integrating remote sensing and 
GIS by object-oriented data modelling. Computers e Graphics, v.20, n.3, p.395-403, 1996.

CÂMARA, G.; MEDEIROS, J. S. de. Geoprocessamento para projetos ambientais. 2.ed. INPE. São José dos Campos, 1998. 194p.

CARVALHO, C. C. N.; ROCHA, W. F.; UCHA, J. M. Mapa digital de solos: Uma proposta metodológica usando inferência fuzzy. Revista Brasileira de Engenharia Agrícola e Ambiental, v.13, n.1, p.46-55, 2009.

CHAVES, I. DE B.; LOPES, V. L.; FFOLLIOTT, P. F.; PAES-SILVA, A. P. Uma classificação morfo-estrutural para descrição e avaliação da biomassa da vegetação da caatinga. Revista Caatinga, v. 21, n. 2, p. 204-213, 2008.

CHAVES, I. DE B.; GUIMARÃES, A. P.; LIMA, E. R. V. DE; FRANCISCO, P. R. M. Índices Espectrais e Diagnóstico da Degradação da Caatinga na Bacia Hidrográfica do Açude Soledade, Paraíba-BR. In: Reunião Brasileira de Manejo e Conservação do Solo e da Água, 19, Lajes-SC. Anais... Lajes, 2012.

COPPIN, P.; JONCKHEERE, I.; NACKAERTS, K.; MUYS, B.; LAMBIN, E. Digital change detection methods in ecosystem monitoring: a review. International Journal of Remote Sensing, v.25, n.9, p. 1565-1596, 2004.

COSTA FILHO, J. F. DA; FRANCISCO, P. R. M.; ANDRADE, M. V. DE; SILVA L. DA; DANTAS, R. L. Estimativa do índice de vegetação da diferença normalizada (NDVI) na microrregião de Sousa-PB utilizando imagens do CBERS-2. In: Congresso Brasileiro de Agrometeorologia, 15, Aracaju-SE. Anais... Aracaju, 2007.

ELVIDGE, C. D.; LYON, R. J. P. Influence of rock-soil spectral variation on the assessment of green biomass. Remote Sensing of Environment, n.17, p.265-279, 1985.

FERNANDES, M. F; BARBOSA, M. P; SILVA, M. J. da. O uso de um sistema de informações geográficas na determinação da aptidão agrícola das terras de parte do setor leste da bacia do Rio Seridó, PB. Revista Brasileira de Engenharia Agrícola e Ambiental, v.2, n.2, p.195-198, 1998.

FRANCISCO, P. R. M. Classificação e mapeamento das terras para mecanização do Estado da Paraíba utilizando sistemas de informações geográficas. 122f. Dissertação (Mestrado em Manejo de Solo e Água). Centro de Ciências Agrárias. Universidade Federal da Paraíba, Areia, 2010.

FRANCISCO, P. R. M.; PEREIRA, F. C.; MEDEIROS, R. M. DE; SÁ, T. F. F. de. Zoneamento de Risco Climático e Aptidão de Cultivo para o Município de Picuí - PB. Revista Brasileira de Geografia Física, v.4, n.5, p.10431055, 2011.

FRANCISCO, P. R. M.; CHAVES, I. DE B.; CHAVES, L. H. G.; LIMA, E. R. V. de. Detecção de Mudança da
Vegetação de Caatinga. Revista Brasileira de Geografia Física, v.5, n.6, p.1473-1487, 2012a.

FRANCISCO, P. R. M.; CHAVES, I. DE B.; LIMA, E. R. V. DE; BANDEIRA, M. M.; SILVA, B. B. da. Mapeamento da caatinga com uso de geotecnologia e análise da umidade antecedente em bacia hidrográfica. Revista Brasileira de Geografia Física, v.5, n.3, p.676693, 2012b.

GUIMARÃES, A. P. Dinâmica da resposta espectral da vegetação de caatinga na bacia hidrográfica do açude Soledade, utilizando técnicas de sensoriamento remoto. Dissertação (Mestrado). Universidade Federal da Paraíba. Areia, 2009.

HUETE, A.; DIDAN, K.; MIURA, T.; RODRÍGUEZ, E. P.; GAO, X.; FERREIRA, L. G. Overview of the radiometric and biophysical performance of the MODIS vegetation index. Remote Sensing of Environment, 83, p.195-213, 2002.

KAUFMAN, Y. J.; HOLBEN, N. B. Calibration of the AVHRR visible and near-IR by atmospheric scattering, ocean glint and desert reflection. International Journal Remote Sensing, v.14, n.1, 1993. p. 21-52.

KUMAR, R. Radiation from plants-reflection and emission: a review. Research Project n.5543. Lafayette: Purdue Research Foundation, 1972. 88p.

LOPES, H. L.; ACCIOLY, L. J. O.; CANDEIAS, A. L. B.; SOBRAL, M. C. Análise de índices de vegetação na bacia do rio Brígida, sertão do estado de Pernambuco. In: Simpósio Brasileiro de Ciências Geodésicas e Tecnologias da Geoinformação, 3, 2010, Recife. Anais... Recife, 2010. p.01-08.

MARKHAM, B. L.; BARKER, J. L. Thematic mapper bandpass solar exoatmospherical irradiances. Int. Journal of Remote Sensing, v.8, n.3, p.517-523, 1987.

MALDONADO, F. D. Desenvolvimento e avaliação de uma metodologia de detecção de mudanças na cobertura vegetal do semiárido. 311p. Tese (Doutorado em Sensoriamento Remoto). São José dos Campos: INPE, 2005.

OLIVEIRA, W. M. DE; CHAVES, I. DE B.; LIMA, E. R. V. de. Índices espectrais de vegetação de caatinga em um neossolo litólico do semiárido paraibano. In: Simpósio Brasileiro de Sensoriamento Remoto,14, 2009, Natal. Anais... Natal: INPE, 2009. p.2103-2110.

PAES-SILVA, A. P.; CHAVES, I. B.; SAMPAIO, E. V. S. B. Cobertura vegetal da bacia hidrográfica do Açude Namorado no cariri oriental paraibano. Agropecuária Técnica. v.24, n.1, p. 47-59, 2003.

PAIXÃO, F. E.; VALE, R. DE M. C. do; LOBÃO, J. . B. Mapeamento de áreas susceptíveis à desertificação no nordeste da Bahia. In: Simpósio Brasileiro de 
Sensoriamento Remoto, 15, 2009, Natal. Anais... Natal: INPE, 2009. p.4195-4200.

PARAÍBA. Secretaria de Estado da Ciência e Tecnologia e do Meio Ambiente. Agência Executiva de Gestão de Águas do Estado da Paraíba, AESA. PERH-PB: Plano Estadual de Recursos Hídricos: Resumo Executivo \& Atlas. Brasília, DF, 2006. 112p.

PARKINSON, C. L. Earth from above. University Sciences Books, Sansalito. Land vegetation, 1997. p.107-111.

SÁ, I. I. S.; GALVÍNCIO, J. D.; MOURA, M. S. B. De; SÁ, I. B. Uso do índice de vegetação da diferença normalizada (IVDN) para caracterização da cobertura vegetal da Região do Araripe Pernambucano. Revista Brasileira de Geografia Física, v.1, n.1, p.28-38, 2008.

SILVA, B. B.; LOPES, G. M.; AZEVEDO, P. V. Determinação do albedo de áreas irrigadas com base em imagens Landsat 5-TM. Revista Brasileira de Agrometeorologia, v.13, n.2, p.11-21, 2005a.

SILVA, B. B.; LOPES, G. M.; AZEVEDO, P. V. Balanço de radiação em áreas irrigadas utilizando imagens Landsat 5 - TM. Revista Brasileira de Meteorologia, v.20, n.2, p.243-252, 2005b.

TROVÃO, D. M. DE B.M.; FERNANDES, P. D.; ANDRADE, L. A. de; DANTAS NETO, J. Variações sazonais de aspectos fisiológicos de espécies da Caatinga. Revista Brasileira de Engenharia Agrícola e Ambiental v.11, n.3, p.307-311, 2007.

VAREJÃO-SILVA M. A.; BRAGA, C. C.; AGUIAR M. J. N.; NIETZCHE M. H.; SILVA, B. B. Atlas Climatológico do Estado da Paraíba. UFPB, Campina Grande, 1984. 